\title{
Free testosterone level in patients with homozygous beta thalassemia on regular transfusions regimen
}

\author{
Riadi Wirawan, MD; Elly Santosa, MD; Lyana Setiawan, MD; \\ Bulan Ginting Munthe, MD; Dalima AW Astrawinata, MD
}

\begin{abstract}
Background Patients with homozygous beta thalassemia require regular transfusions which will lead to iron deposition in tissues including testicles.

Objective This study aimed to evaluate testicular function in synthesizing testosterone by measuring free testosterone level. The correlation between free testosterone level and transferrin saturation was evaluated.

Methods This was a cross sectional study. Sampling was done consecutively. Free testosterone level was measured by radioimmunoassay in 20 homozygous beta thalassemic patients receiving regular transfusions and compared to 20 healthy subjects.

Results Fourteen out of 20 patients showed free testosterone level below the reference range. Out of 20 thalassemic patients, one patient's serum was not enough for transferrin saturation determination. Among the 19 patients, 18 had transferrin saturation above $55 \%$, 1 less than $55 \%$, while all healthy subjects had normal transferrin saturation. A significant difference was found between the two groups, both in the free testosterone level $(p=0.001)$ and transferrin saturation $(p<0.001)$. A very weak correlation was found between free testosterone level and transferrin saturation $(r=-0.215)$. Conclusion We concluded that there might be a relationship between iron overload and testicular endocrine function in patients with homozygous beta thalassemia receiving regular transfusions [Paediatr Indones 2004;44:73-79].
\end{abstract}

Keywords: homozygous beta thalassemia, regular transfusions, iron overload, free testosterone level

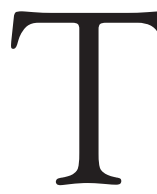
halassemia is the most common genetic disorder characterized by a defect in the globin synthesis resulting in reduced or no production of one or more globin chain. Among thalassemias, beta thalassemia is the most important, considering its prevalence and the severity of anemia in homozygous and mixed heterozygous state. ${ }^{1}$ This disease is widespread through the Mediterranean, Africa, Middle East, India, and South East Asia, including Southern China and Indonesia. ${ }^{2}$ Patients with homozygous beta thalassemia suffer from severe anemia resulted from hemolysis and ineffective erythropoiesis, and need regular transfusions. ${ }^{1,3}$ Regimen of regular blood transfusions will eventually lead to iron overload, which will in turn result in multiple organ dysfunction, including liver, kidney, and endocrine organs. ${ }^{1,4}$

Approximately $80-90 \%$ of patients with homozygous beta thalassemia suffer from growth retardation, delayed puberty, and infertility due to pituitary, adrenal, gonadal, and testicles disorders. ${ }^{3}$ Although evidences shown by various studies had suggested this, ${ }^{3,5}$ there had been no data on how regular transfusions regimen affects the testicular function in Indonesian subjects with beta thalassemia. Free testosterone level is considered to be better in reflecting gonadal hormone activity since it is the biologically active form. ${ }^{6}$ Moreover, with the advance of laboratory methods, assays for free

From the Departments of Clinical Pathology (RW, ES, LS, DAWA) and Pediatrics (BGM), Medical School, University of Indonesia, Cipto Mangunkusumo Hospital, Jakarta

Reprint requests to: Riadi Wirawan, MD, Department of Clinical Pathology, Medical School, University of Indonsia, Jakarta, Jalan Salemba 6, Jakarta 10430. Tel: 62-21-3147342, Fax. 3907743 
testosterone are now available. In this study, we evaluated testicular endocrine function by measuring free testosterone level in Indonesian homozygous beta thalassemic subjects who received regular transfusions and assessed the correlation between iron overload reflected by transferrin saturation and free testosterone level in those subjects.

\section{Methods}

This was a cross-sectional study. Sampling of the subjects was done consecutively during JuneAugust 2001. We obtained sera from 20 male subjects aged $14-25$ year-old with homozygous beta thalassemia who had received regular transfusions of six units or more of packed red cells in a period of six months at the Thalassemia Center, Department of Child Health, Cipto Mangunkusumo Hospital, and from 20 healthy male subjects from the same age group. The blood was taken in the morning before the patients received his transfusion. Serum was separated, frozen, and stored no longer than 2 months until assayed.

The determination of free testosterone level was done by radioimmunoassay (RIA) method using the "Free Testosterone" Coat-A-Count reagent from Diagnostic Products Corporation (DPC) as described in the manufacturer's leaflet. ${ }^{7}$ Precision and accuracy of the assay was evaluated using CON6, the control material from DPC. ${ }^{8}$

We also determined the level of serum iron and total iron binding capacity to assess the relationship between iron overload reflected by the transferrin saturation and free testosterone level.

Statistical analysis was done using SPSS 10.0 for Windows and STATA. To analyze data distribution, Kolmogorov-Smirnov test was used. If the distribution was Gaussian, Student t-test was done to assess whether there was any significant difference between the free testosterone levels of the two groups; if the data distribution was not Gaussian, then Mann-Whitney test was used. Pearson's correlation test was used to assess the correlation between free testosterone level and transferrin saturation if the distribution was normal, and Spearman-rho test was used for non-Gaussian distribution. ${ }^{9}$

\section{Results}

Before running the tests, the precision and accuracy of the assay was tested with CON6 control material; intra-assay precision was good, $6.27 \%$ and $2.03 \%$ for low and normal levels, respectively.

Of twenty male thalassemic patients, only 19 sets of data were obtained, as 1 patient's serum was not enough for subsequent transferrin saturation determination. Four out of 20 patients had free testosterone levels within the reference range $(8.8-27 \mathrm{pg} / \mathrm{ml})^{7}$, 2 patients above reference range, and 14 patients below reference range. Eighteen patients had transferrin saturation of more than $55 \%$ and only 1 patient had transferrin saturation of less than 55\%. The age, free testosterone level, and transferrin saturation of the thalassemic group are listed in Table 1 .

All 20 healthy subjects had transferrin saturation below 55\%. Fifteen out of those 20 subjects had free testosterone levels within the reference range, four above reference range, and one below reference range (see Table 2 and Figure 1).

Statistical analysis yielded a non-Gaussian distribution of free testosterone level and transferrin saturation in the thalassemic group and a Gaussian distribution in the healthy subject group.

Table 1. Age, free testosterone level and TRANSFERRIN SATURATION OF THE THALASSEMIC GROUP

\begin{tabular}{lccc}
\hline No. & Age (years) & $\begin{array}{c}\text { Free testosterone } \\
(\mathbf{p g} / \mathbf{m l})\end{array}$ & $\begin{array}{c}\text { Transferrin } \\
\text { saturation (\%) }\end{array}$ \\
\hline $1^{*}$ & 14 & 0.5 & - \\
2 & 14 & 0.55 & 66.8 \\
3 & 15 & 1.9 & 96.2 \\
4 & 15 & 0.5 & 84.4 \\
5 & 15 & 0.55 & 70.5 \\
6 & 16 & 7.5 & 88.4 \\
7 & 16 & 0.55 & 66.3 \\
8 & 17 & 4.8 & 79.7 \\
9 & 18 & 6.2 & 77.3 \\
10 & 18 & 22.0 & 67.5 \\
11 & 18 & 2.9 & 71.0 \\
12 & 19 & 17.0 & 51.7 \\
13 & 19 & 30.0 & 66.3 \\
14 & 21 & 22.0 & 82.5 \\
15 & 21 & 1.1 & 83.3 \\
16 & 21 & 4.0 & 68.3 \\
17 & 21 & 0.5 & 85.1 \\
18 & 22 & 3.4 & 78.7 \\
19 & 22 & 29.0 & 80.9 \\
20 & 24 & 14.0 & 84.1 \\
Mean & 18.3 & $\mathbf{8 . 8 7}$ & $\mathbf{7 6 . 2 6}$ \\
SD & $\mathbf{3 . 0}$ & $\mathbf{1 0 . 1 7}$ & $\mathbf{1 0 . 4 7}$ \\
\hline
\end{tabular}

* Serum not enough for transferrin saturation determination 
There was a significant difference in free testosterone levels between both groups $(p=0.001)$. A significant difference was also observed in transferrin saturation between the two groups $(\mathrm{p}<0.001)$. There was a weak correlation between age and free testosterone levels $(\mathrm{r}=0.512)$ in all subjects, including that in the thalassemic group $(r=0.418)$. A very weak correlation was noted between age and transferrin saturation in the thalassemic group $(\mathrm{r}=0.08)$, and a very weak negative correlation was also observed between free testosterone level and transferrin saturation in the thalassemic group $(\mathrm{r}=-0.215)$

Table 2. Age, free testosterone leVel and TRANSFERRIN SATURATION OF THE HEALTHY SUBJECTS

\begin{tabular}{lccc}
\hline No. & Age (years) & $\begin{array}{c}\text { Free testosterone } \\
\text { (pg/ml) }\end{array}$ & $\begin{array}{c}\text { Transferrin } \\
\text { saturation }\end{array}$ \\
\hline 1 & 14 & 8.0 & 37.7 \\
2 & 14 & 9.0 & 36.2 \\
3 & 17 & 16.0 & 32.3 \\
4 & 19 & 23.0 & 24.0 \\
5 & 19 & 19.0 & 29.2 \\
6 & 20 & 9.0 & 30.9 \\
7 & 21 & 30.0 & 38.5 \\
8 & 22 & 30.0 & 34.7 \\
9 & 22 & 23.0 & 25.2 \\
10 & 23 & 25.0 & 32.4 \\
11 & 23 & 16.0 & 40.7 \\
12 & 23 & 23.0 & 36.5 \\
13 & 24 & 23.0 & 33.1 \\
14 & 24 & 38.0 & 38.2 \\
15 & 24 & 9.0 & 24.9 \\
16 & 24 & 15.0 & 38.6 \\
17 & 25 & 11.0 & 38.4 \\
18 & 25 & 12.0 & 40.1 \\
19 & 25 & 30.0 & 38.7 \\
20 & 25 & 13.0 & 33.3 \\
Mean & $\mathbf{2 1 . 7}$ & $\mathbf{1 9 . 1 0}$ & $\mathbf{3 4 . 1 8}$ \\
SD & $\mathbf{3 . 5}$ & $\mathbf{8 . 6 7}$ & $\mathbf{4 . 8 1}$ \\
\hline
\end{tabular}

\section{Discussion}

Thalassemia was first clinically described by Thomas Cooley in Detroit in 1925.1,4 It is characterized by hemolytic anemia and splenomegaly. Subsequently, thalassemia is also designated as Cooley's anemia. ${ }^{1}$

Regular transfusions are given to compensate anemia. The recent management of thalassemia consists of regular transfusions regimen and chelation therapy which allow patient to live almost a normal life. ${ }^{10,11}$ Repeated transfusions will eventually lead to iron overload and cause toxicity resulted from free radical formation which produces tissue damage due to oxidative process in the organs where iron accumulates. Moreover, iron overload is aggravated by increased iron absorption in the gut and ineffective erythropoiesis which causes a drastic increase in the plasma iron turnover up to $10-15$ times normal. ${ }^{12}$

There are several methods to diagnose iron overload or hemochromatosis. Body iron stores can be assessed with a number of parameters i.e., hepatic iron stores, ferritin level, and transferrin saturation calculated from serum iron level and total iron binding capacity (TIBC). ${ }^{13}$ The determination of hepatic iron stores is difficult and invasive, though can be assessed alternatively by radiological means (i.e., magnetic resonance imaging/MRI). Ferritin level is not a good predictor of iron overload compared to hepatic iron assessment as it is an acute phase protein, which means that its level is affected by inflammatory responses. ${ }^{14}$ Transferrin saturation, on the other hand, is a good indicator of body iron stores. Transferrin saturation of $55 \%$ or more associated with increased ALT and AST of more than twice normal value is diagnostic for hemochromatosis. ${ }^{15}$

In iron overload, iron is deposited in almost every tissue, but particularly in two types of cells i.e., reticuloendothelial and parenchymal cells. Accumulation in reticuloendothelial cells can be found in the spleen, liver, and bone marrow, while parenchymal deposits are found especially in the liver, endocrine organs, and muscle. ${ }^{2.13}$ Endocrine organ functions are usually affected, including organs that produce hormones for growth and sexual development. ${ }^{16}$

In male, testosterone is the most abundant sex hormone. It is responsible for the embryonic differentiation of external and internal genital organs in male fetus, and in puberty, it supports the development and maintains the function of scrotum, epididymis, vas deferens, seminal vesicle, and penis. In adult male, it maintains libido and potency. ${ }^{6}$

Sex hormone circulates in two forms i.e., bound and free. About $38 \%$ of circulating testosterone was bound to albumin and 60\% to sex hormone binding globulin (SHBG). The remaining 2\% is found as free testosterone and capable of entering the target cell to exert metabolic activity. ${ }^{17}$ The free testosterone can be determined by RIA method, ${ }^{7,17}$ calculated from total testosterone and SHBG levels using a formula ${ }^{18}$ or chemiluminescence method. ${ }^{19}$ The formula for calculation of free testosterone level is free testoster- 


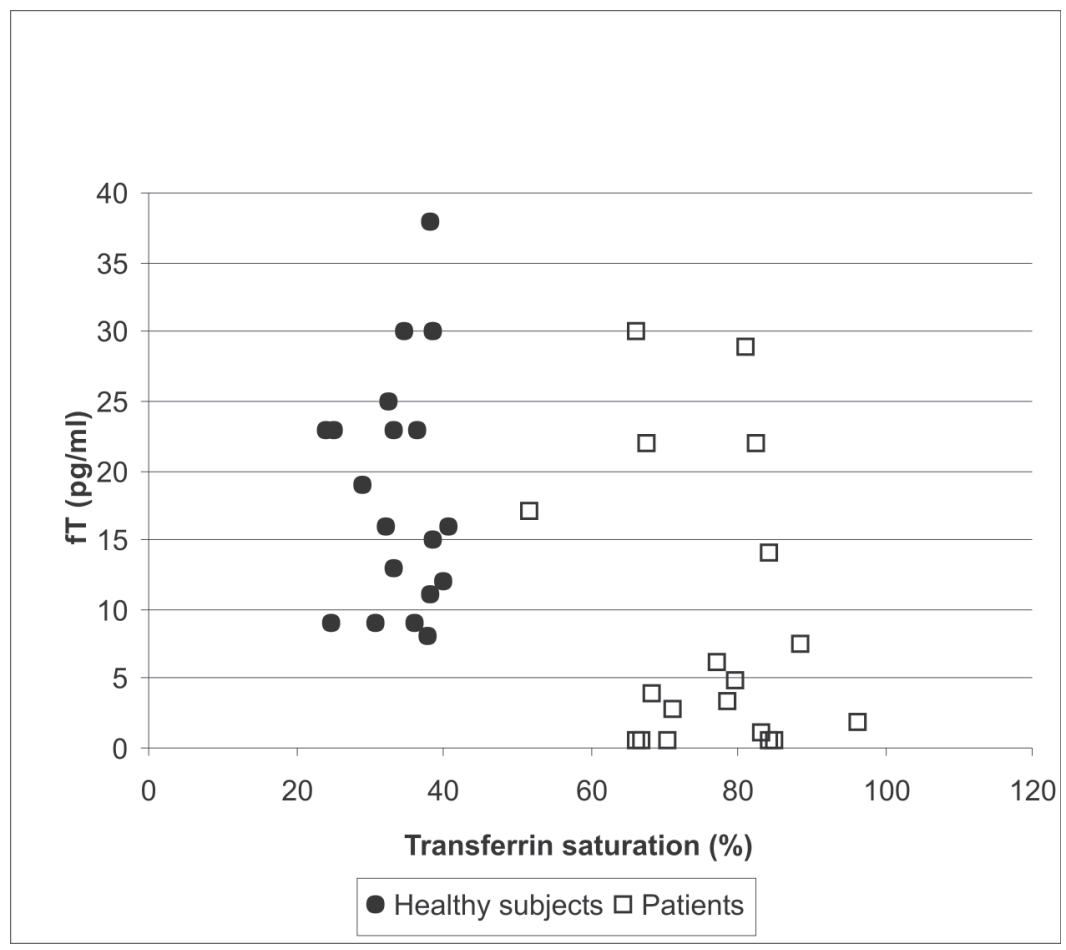

FT = free testosterone level

Figure 1. Relationship between free testosterone level and transferrin saturation of the two groups. Thalassemic patients are plotted as clear boxes, while healthy subjects as circles.

one $(\mathrm{pmol} / \mathrm{L})=$ total testosterone $(\mathrm{nmol} / \mathrm{L}) /(\mathrm{K} x$ SHBG $(\mathrm{nmol} / \mathrm{L})+1) \times 1000 ; \mathrm{K}\left(1.6 \times 10^{9} \mathrm{~L} / \mathrm{mol}\right)$ is the equilibrium constant of testosterone binding to SHBG. ${ }^{18}$ Free testosterone level is considered better for clinical application as it is the active form. ${ }^{17}$

In Indonesia, most thalassemic patients on regular transfusions have not had proper chelation therapy, which may lead to a high incidence of hemochromatosis and consequently, to impaired endocrine organ function. So far, there had been no report of free testosterone level in Indonesian $\beta$-thalassemic patients compared to healthy subjects, which was evaluated in this study. Also evaluated was the relationship between free testosterone level and transferin saturation which reflects body iron stores.

Our subjects were twenty Indonesian $\beta$ thalassemic male patients on regular transfusions, aged 14-25 year-old, and 20 healthy Indonesian male from the same age group. Cutoff point for age was based on the onset of puberty in male; at 14 years old, approximately $98 \%$ of boys have achieved puberty. ${ }^{20}$ Crite- rion for regular transfusions was based on Lee et al, as quoted by Wirawan et al ${ }^{21}$ which was transfusion of a minimum o6 unit packed cells in 6 months.

Determination was done on a single sample collection for each patient, as single determination is sufficient to distinguish patients with hypogonadism. ${ }^{17,20}$ RIA method is chosen as it is simple and does not require isolation of the free fraction prior to assay, is quick and can detect as low as $0.15 \mathrm{pg} / \mathrm{ml}$ free testosterone levels. Almost no cross-reactivity with other blood steroid had been reported with this method, and if present, it is very small $(<0.01 \%)^{7}, 22$

Prior to testing, pipettes used for testing were calibrated yielding a good precision and accuracy, which is still in the $\mathrm{WHO}^{23}$ allowed range i.e., $<2 \%$ for CV. Precision and accuracy testing was also performed using control materials from DPC. Two levels of control were used, the low abnormal and normal control. Within run precision testing with low abnormal control and normal control yielded CVs of $6.27 \%$ and $2.03 \%$ respectively. These results are comparable 
Riadi Wirawan et al: Free testosterone level in homozygous beta thalassemics on regular transfusions

to those of van den Beld et $a^{24}$, which was $6.2 \%$ for normal range, and Garde et al ${ }^{25}$ which was $7.2 \%$. Better precision is obtained for testing the normal level, which is in accordance with the nature of RIA tests, which yielded low CV near the middle point of testing range and higher CV at a lower or higher concentration. ${ }^{26}$

In accuracy testing, all the control values fit into the allowed range, which produced good accuracy. Deviations to the real control value were $19.8 \%$ and $17.1 \%$ respectively for low abnormal and normal control.

In the thalassemic patients group, 14 out of 20 patients had testosterone levels below reference range. This result implied that the testicular endocrine function might be impaired in those patients. Yet, the proportion was bigger compared with the findings of Borgna-Pignatti et al ${ }^{11}$ who reported a prevalence of clinical hypogonadism in 55\% of male and female subjects, and Kattamis et al ${ }^{16}$ who reported a prevalence of $42 \%$ in male subjects. Both studies only assessed the clinically found hypogonadism, while not all subjects with low level of sex hormone will show signs of hypogonadism, which explains the greater proportion found in this study. Moreover, there might be a significant difference between the reference value for Indonesian people and that of the population studied by Ooi et al whose study was quoted by DPC. ${ }^{7}$ Winters et al 27 reported a higher range of free testosterone level in his study, ranging from $18.2-57.2 \mathrm{pg} / \mathrm{ml}$. These differences might be due to the differences in the population studied, population sampling method, laboratory techniques, and physiological factors.

One out of 19 thalassemic patients had transferrin saturation of less than 55\%; while the other 18 had transferrin saturation of more than $55 \%$. The high prevalence suggested that hemochromatosis might be present and might have caused testicular endocrine dysfunction. All patients with low free testosterone level had high transferrin saturation. Six patients had normal or high free testosterone level; 1 (patient no. 12) had transferrin saturation of less than $55 \%$ and 3 (patients no. 10,12 and 13) had transferrin saturation of less than the group's average (76.26\%). The normal or above normal level of testosterone might be related to the possibility that the patients had not suffered from hemochromatosis or had chelation therapy. The six patients are summarized in Table 3.
Table 3. Patients With normal or high testosterone LEVELS

\begin{tabular}{lccc}
\hline No. & Age (year) & $\begin{array}{l}\text { Free testosterone } \\
\text { level }(\mathbf{p g} / \mathbf{m l})\end{array}$ & $\begin{array}{l}\text { Transferrin } \\
\text { saturation (\%) }\end{array}$ \\
\hline 10 & 18 & 22.0 & 67.5 \\
12 & 19 & 17.0 & 51.7 \\
13 & 19 & 30.0 & 66.3 \\
14 & 21 & 22.0 & 82.5 \\
19 & 22 & 29.0 & 80.9 \\
20 & 24 & 14.0 & 84.1 \\
\hline
\end{tabular}

Statistical analysis revealed a significant difference $(p=0.001)$ between the free testosterone levels of the thalassemic and healthy subjects. Free testosterone levels were significantly lower in the thalassemic group compared with the healthy subjects, which support the findings of Borgna-Pignatti et $a l^{11}$ and Kattamis et al. ${ }^{16}$ A significant difference $(\mathrm{p}<0.001)$ of transferrin saturation was also found between the thalassemic group and those of the healthy group, which showed that iron overload was present in thalassemic patients.

Correlation studies showed weak correlation between age and free testosterone levels in all subjects $(r=0.512)$ and in the thalassemic group $(\mathrm{r}=0.418)$. In this study, low free testosterone levels were observed in the patients with transferrin saturation of as low as $66.3 \%$. Yet, other subjects with comparable transferrin saturation had normal free testosterone level. Very weak negative correlation was found between free testosterone level and transferrin saturation in the thalassemic group $(\mathrm{r}=$ 0.215), which implied that the correlation might be affected by other factors, such as SHBG and albumin, which are synthesized by the liver. ${ }^{6}$ Roesli ${ }^{28}$ reported impaired liver function, especially synthesis function, in up to $84.4 \%$ of thalassemic patients on regular transfusions. Roesli ${ }^{28}$ also reported a decreased serum albumin in $9.4 \%$ of those patients. The low albumin level might affect the free testosterone level. Better correlation may also be obtained if the number of subjects studied is bigger.

Almost no correlation was found between age and transferrin saturation in the thalassemic group $(\mathrm{r}=0.08)$. This finding might be due to the biological variation in transfusion requirement, iron absorption, and factors that influence it between individuals, which affect the development of hemochromatosis, and the possibility of chelation therapy. 
All control subjects had normal transferrin saturation. Only one subject had low free testosterone level compared to the reference range. The subject was 14 years old; It was possible that he might not had reached his onset of puberty as the only $98 \%$ of boys have reached their onset of puberty at the age of $14 .{ }^{20}$ Moreover, the free testosterone level was only modestly below the lower range ( 8.0 versus $8.8 \mathrm{pg} /$ $\mathrm{ml}$ ), which might prove to be normal in Indonesian male.

Statistical analysis showed a significant difference between free testosterone levels of the thalassemic and control groups $(p=0.001)$, and between transferrin saturation of both groups $(\mathrm{p}<0.001)$. These results showed that there was a higher prevalence of testicular endocrine dysfunction and iron overload in thalassemic patients compared with those of healthy subjects. Although the correlation between the two parameters above was weak, those findings might still suggest that there was a correlation between the development of hemochromatosis and the low free testosterone level in $\beta$-thalassemic patients on regular transfusions.

Regular transfusions in thalassemic patients lead to iron overload, which will eventually result in organ dysfunction. This finding may support the need of transferrin saturation examination in those patients and, if proven high, we recommend to test the free testosterone level to assess gonadal endocrine status in male thalassemic patients.

As a conclusion, free testosterone levels were significantly lower in the thalassemic group compared with those of the healthy subjects. Transferrin saturation of $>55 \%$ was found in 18 out of 19 patients, while all healthy subjects had normal levels. Weak correlation was observed between the two parameters which may be better if the number of subjects was bigger. The results suggested that there might be a correlation between the development of hemochromatosis and the low free testosterone level in b-thalassemic patients on regular transfusions, which may be dependent on other factors. We suggested that thalassemic patients on regular transfusions be tested for their transferrin saturation, and if the transferrin saturation is high, proceed with the free testosterone level assay. Further studies to establish the reference value of free testosterone level for Indonesian male are recommended.

\section{References}

1. Weatherall DJ. Genetic disorders of the haemoglobin. In: Hoffbrand AV, Lewis SM, Tuddenham EGD, editors. Postgraduate Haematology. $4^{\text {th }}$ ed. Oxford: Butterworth-Heinemann; 1999. p. 91-119.

2. Olivieri NF. The $\beta$-Thalassemias. N Engl J Med 1999;341:99-109.

3. Chatterjee R, Katz M. Reversible hypogonadotrophic hypogonadism in sexually infantile male thalassaemic patients with transfusional iron overload. Clin Endocrinol 2000;53:33-8.

4. McKenzie SB. Anemias caused by abnormalities in globin biosynthesis. In: McKenzie SB. Textbook of Hematology. $2^{\text {nd }}$ ed. Baltimore: Williams and Wilkins; 1996. p.147-78.

5. Italian Working group on endocrine complications in non-endocrine diseases. Thalassemia and endocrinopathies: Multicenter study of 3092 patients. In: Ando S, Brancati C, editors. Endocrine Disorders in Thalassemia. Berlin: Springer-Verlag; 1995. p. 91-3

6. Guyton AC. Reproductive and hormonal functions of the male. In: Guyton AC editor. Textbook of Medical Physiology. $8^{\text {th }}$ ed. Philadelphia: WB Saunders; 1991. p. 885-98.

7. Coat-A-Count Free Testosterone [leaflet]. Diagnostic Products Corporation, Los Angeles, 1999.

8. CON6 [leaflet]. Diagnostic Products Corporation, Los Angeles, 1999

9. Saunders DB, Trapp GR. Estimating and comparing means. In: Basic Clinical Biostatistics. Canada: Appleton-Lange; 1994. p. 896-909.

10. Piomelli S. The management of patients with Cooley's anemia: Transfusions and splenectomy. Semin Hematol 1995;32:262-8.

11. Borgna-Pignatti C, Rugolotto S, De Stefano P, Piga A, Di Gregorio F, Gamberini MR, et al. Survival and disease complications in thalassemia major. Ann NY Acad Sci 1998;850:227-31.

12. Hershko C, Link G, Cabantchik I. Pathophysiology of iron overload. Ann NY Acad Sci 1998;850:191-201.

13. Weatherall DJ, Clegg JB. Genetic disorders of hemoglobin. Semin Hematol 1999;36(Suppl 7):24-37.

14. Sherwood RA, Pippard MJ, Peters TJ. Iron homeostasis and the assessment of iron status. Ann Clin Biochem 1998;35:693-708.

15. Powell LW, George K, McDonnell SM, Kowdley KV. Diagnosis of hemochromatosis. Ann Intern Med 1998;129:925-31. 
Riadi Wirawan et al: Free testosterone level in homozygous beta thalassemics on regular transfusions

16. Kattamis CA, Kattamis AC. Management of thalassemias: growth and development, hormone substitution, vitamin supplementation, and vaccination. Semin Hematol 1995;32:269-79.

17. Braunstein GD. Testes. In: Greenspan FG, editor. Basic and Clinical Endocrinology. $3^{\text {rd }}$ ed. London: Appleton-Lange; 1991. p.407-41.

18. Wilke TJ, Utley DJ. Total testosterone, free-androgen index, calculated free testosterone, and free testosterone by analog RIA compared in hirsute women and in otherwise-normal women with altered binding of sex-hormonebinding globulin. Clin Chem 1987;33:1372-5.

19. Caglayan S, Ozata M, Osizik G, Turan M, Bolu E, Oktenli $\mathrm{C}$, et al. Plasma melatonin concentration before and during testosterone replacement in Klinefelter's Syndrome: relation to hepatic indolamine metabolism and sympathoadrenal activity. J Clin Endocrinol Metab 2001;86:738-43.

20. Kasa-Vubu JZ, Kelch RP. Precocious and delayed puberty: diagnosis and treatment. In: DeGroot LJ, Besser M, Burger HG, Jameson JL, Loriaux DL, Marshall JC, et al, editors. Endocrinology. $3^{\text {rd }}$ ed. Philadelphia: WB Saunders Company; 1997. p. 1953-77.

21. Wirawan R, Kusnandar S, Suherli A, Gatot D. Renal impairment in $\beta$-thalassemia major patients receiving repeated blood transfusion. Med J Indones In press 2003.
22. Cheng RW,ReedMJ,James VHT.Plasmafree testosterone: equilibrium dialysis vs direct radioimmunoassay. Clin Chem 1986;32:1411.

23. Lewis SM. Quality assurance in haematology. WHO/ $\mathrm{Lab} / 98.4$

24. Van den Beld AW, de Jong FH, Grobbee DE, Pols HAP, Lamberts SW. Measures of bioavailable serum testosterone and estradiol in their relationships with muscle strength, bone density and body composition in elderly men. J Clin Endocrinol Metab 2000;85:3276-82.

25. Garde AH, Hansen AM, Skovgaard LT, Christensen JM. Seasonal and biological variation of blood concentrations of total cholesterol, dehydroepiandrosterone sulfate, hemoglobin $A_{1 c}$, IgA, prolactin, and free testosterone in healthy women. Clin Chem 2000;46:551-9 .

26. Stites DP, Rodgers RPC. Clinical laboratory methods for detection of antigens and antibodies. In: Stites DP, Terr, AI, editors. Basic and Clinical Immunology. $6^{\text {th }}$ ed. London: Appleton \& Lange; 1987. p. 241-85.

27. Winters SJ, Kelley DE, Goodpaster B. The analog free testosterone assay: are the results in men clinically useful? Clin Chem 1998;44:2178-82.

28. Roesli T. Gangguan fungsi hati pada penderita thalassemia b mayor: telaah khusus hubungan dengan saturasi transferin dan infeksi virus hepatitis hepatitis $\mathrm{B} \& \mathrm{C}$ [thesis]. Jakarta: Departments of Clinical Pathology, Medical School, University of Indonesia; 2001. 